\title{
Intensive Care Unit Nurses' Uncertainty and Patient Safety Culture
}

\author{
Safaa M. El-Demerdash ${ }^{1} \&$ Heba K. Obied ${ }^{1}$ \\ ${ }^{1}$ Nursing Administration Department, Faculty of Nursing, Tanta University, Egypt \\ Correspondence: Heba K. Obied, Nursing Administration Department, Faculty of Nursing, Tanta University, \\ Egypt. E-mail: hebaobied@yahoo.com
}

Received: February 1, 2018

Accepted: March 3, 2018

Online Published: March 20, 2018

doi:10.20849/ijsn.v3i1.345

URL: https://doi.org/10.20849/ijsn.v3i1.345

\begin{abstract}
Intensive care unit (ICU) nurses face many uncertain situations that may affect their patient care decisions and jeopardize patients' safety.

Aim: This study aimed to explore the relationship between uncertainty and patient safety culture among intensive care unit nurses at Tanta Main University Hospital.

Study subject: included (155) nurses worked in intensive care units at Tanta University Main Hospital. Two tools were used Tool (I): Nurses' Uncertainty Questionnaire. Tool (II): Patient Safety Culture Questionnaire.

Results: $74.2 \%$ of participant ICU nurses' experienced high levels of uncertainty. Above half $(56.1 \%$ and $56.1 \%)$ of them always experienced being uncomfortable and confused\& loss of control when facing uncertain situations in ICUs. $84.5 \%$ and $76.8 \%$ of them always used team work; and learn from past experience to deal with uncertainty. $47.1 \%$ of them evaluated patient safety in their ICUs as acceptable and bad. There was a high statistical negative correlation between the levels of patient safety culture and experiencing uncertainty by ICU nurses at $\mathrm{p}=0.000$.

Conclusions: ICU nurses experienced high level of uncertainty; they rely on experience and teamwork rather than evidence-based practices to manage clinical uncertainty. High statistical significant negative correlation was found between patient safety culture and experiencing uncertainty by ICU nurses.
\end{abstract}

Keywords: intensive care units, nurses, uncertainty, and patient safety culture

\section{Introduction}

Intensive care units (ICUs) have been viewed as highly complex areas, where nurses have to work with critically ill patients and sophisticated equipments that involve higher levels of stress and uncertainty than other hospital units. ICU nurses face many challenges stem from complexity of patient diagnosis, intense patient needs, nursing shortage, limitation of time and healthcare team interdependence that cause uncertainty (Thompson \& Dowding, 2001).

Uncertainty has been identified as different possible outcomes for a certain situation but complexity makes it hard to identify the appropriate set of options (LeGuin, 2013). Furthermore uncertainty means lack of information required to perform work tasks or to make decisions (McGonigal-Kenney, 2011). Nurses' lack of information can be viewed in different forms; incomplete information of the work area manifested in decreased confidence in judgmental abilities, inadequate information of the current empirical data to support certain intervention, and finally inability to differentiate between the limitation of a person's own knowledge and the limitations of current knowledge (Thompson and Dowding, 2001).

Uncertainty can emerge from different sources including differences in healthcare staff mental maps and norms, non-rational behaviors, technical and social complexity of ICU that lead to interdependency of actions (LeGuin, 2013). Earlier (Beresford, 1991) specified three sources of uncertainty technical source including inadequate information for precisely predict prognosis or interventions outcomes, personal source including inadequate knowledge regarding patient's desires or concerns, and conceptual source including applying general criteria for specific situations (Cranley, 2009).

ICU nurses' have to make several patient care decisions rapidly to respond to patient needs. These decisions are greatly affected by uncertainty, where patients are critically ill and their health conditions seriously unstable. 
Nurses' have to choose between numerous alternatives vary in usefulness and probability of its expected outcomes (Grote, 2009).

Nurses' responses to uncertainty vary it may include cognitive responses through using decision making process, relying on intuition, or even recalling information from past experience, and working as a team. Affective responses, experiencing uncertainty accompanied with stress, feeling incompetent, denial, avoidance behaviors, as well as intolerance of ambiguity and reluctance to disclose uncertainty. Behavioral responses including gathering additional information, and rely on evidence-based information, working on oneself by seeking continuing education (Cranley, 2009). Moreover responses to uncertainty elucidate the coping strategies utilized to manage uncertainty. Uncertainty influence nurses' clinical decisions and put patient safety at risk as well as the overall quality of nursing care provided to patients.

Patient safety focuses on providing safe patient care and preventing errors as well as adverse events results from care interventions. Therefore healthcare organizations adopt patient safety culture to guide the nurses' practice in ICUs (Thompson and Dowding, 2001). Safety culture is combination of individual and group values, attitude, perception, and competencies, that shape the pattern of behavior represents organizational proficiency (McGonigal-Kenney, 2011). Patient safety culture is concerned with delivering patient care through precision in each step of nursing-care starting with comprehensive patient assessments, planning, implementing proper care, and ongoing evaluations to prevent potential errors. Patient safety culture has become the prime importance of any healthcare organization, thus nurses need to know how to confront uncertainty of daily practice to reduce error rates and maintain high level of patient safety (Grote, 2009).

Patient safety culture is characterized by providing opportunity for continuous improvement\& organizational learning, hospital units to work in teams; ensure appropriateness of the work conditions as well as staffing levels. In addition positive safety culture focuses' on supervisors' actions to promote safety, provide feedback about error, ensure communication openness, overall staff perception of safety, management support for safety, hospital handoffs \& transitions and non-punitive response to error (Aboul-Fotouh et al., 2012).

During daily practice ICU nurses can eliminate the influence of uncertainties through continuing education, supervision, consultation and working with other professionals, and learn to make logical as well as ethical decision making (Striefel, 2006). Adding to that the availability of information, sharing a common sense, caution, and persistence are crucial to reduce uncertainties. Uncertainty facing ICU nurses is under-described in nursing literature. Thus understanding sources of uncertainty, how ICU nurses deal with it and how uncertainty affects patient safety culture is crucial to control uncertainty and eliminate patient errors and allow hospitals administration to recognize strengths and weaknesses of their organizational safety culture.

\subsection{Aim of the Study}

The present study aimed at exploring the relationship between uncertainty and patient safety culture among intensive care unit nurses at Tanta Main University Hospital.

\subsection{Research Questions}

1. What is the level of uncertainty among intensive care unit nurses?

2. What is the level of patient safety culture among intensive care unit nurses?

3. Is there a relationship between uncertainty and patient safety culture among ICU nurses?

\section{Subjects \& Method}

\subsection{Design}

Descriptive -correlation research design was used.

\subsection{Setting}

The study was conducted in intensive care units at Tanta University Main Hospital included medical, cardiac, neuro, anesthesia, pediatric, and chest ICU.

\subsection{Subject}

155 ICU nurses were working in the previously mentioned settings and willing to participate in the study. During their work shifts, they completed the self administered questionnaires in the presence of the researchers.

\subsection{Tools}

To achieve present study aims the following two tools were used. 
Tool (I): ICU Nurses' Uncertainty Questionnaire. This tool was developed by the researchers and guided by Cranley (2009)' Striefel (2006), Sayed \& Ibrahim (2012), and Sheer\& Cline (1995) to collect data from ICU nurses about uncertainty in their working units. It consisted of four parts.

First: Nurses' personal data included age, marital status, educational level, working unit, years of experience and attended training courses last year.

Second: ICU Nurses' Uncertainty Questionnaire. It encompassed uncertain situations related to patients (10 items), uncertain situations related to nurses (18 items) and uncertain situations related to environment (8items). Scoring system, ICU nurses' responses were measured in three points Likert Scale ranging from disagree $=1$, uncertain $=2$, and agree $=3$. The respondents total scores were classified into two levels, high $\geq 50 \%$ and low $<50 \%$.

Third: ICU Nurses' Response to Uncertainty, it consisted of (8 items). Fourth: Nurses' Strategies to Deal with Uncertainty, it included (10 items). Scoring system: for third and fourth parts nurses' responses were measured in three points Likert Scale ranged from rarely $=1$, sometimes $=2$, always $=3$.

Tool (II): Patient Safety Culture Questionnaire. This tool adopted from Agency for Healthcare Research and Quality's hospital survey (2008) on patient safety culture. It was used to identify participants' perception regarding patient safety culture, included nurses' assessment of patient safety culture in their ICUs and frequency of reporting negative events in ICUs. It encompassed eleven dimensions of patient safety culture included; continuous improvement (3items), intra-unit teamwork (4 items), staff availability \& work conditions (4 items), supervisory measures to sustain safety (4 items), feedback regarding error (3 items), inter-units teamwork (4 items), open channels of communication (3 items), organizational awareness of safety (4 items), management role to sustain safety (3 items), control patient transition \& handoffs (4 items) and response to error (3 items). Scoring system: nurses' responses were measured on a 3-points Lickert scale agree $=3$ uncertain $=2$, and disagree $=1$. The total ICU nurses' responses of patient safety culture were classified into two levels high $\geq 50 \%$ and low $<50 \%$.

\subsection{Procedures}

The tools were translated into Arabic and reviewed by 3 experts in nursing administration and 2 experts in psychiatric nursing from Faculty of Nursing- Tanta University. The tools were modified based on experts' comments. A pilot study was conducted on (16 ICU nurses) were excluded from the actual study sample; to ensure the clarity of the tools and to estimate the required time for completing the tools. Reliability of the tools (1and 2) was tested using Cronbach's alpha coefficient test, its value was 0.88 and 0.95 for tool 1 and 2 respectively. The data collection phase persisted for three months (November 2015- January 2016)

\subsection{Ethical Considerations}

The researchers obtained an official permission from Tanta University Hospitals' responsible authorities to carry out the study. Researchers met the participant ICU nurses during their work shifts and explained the purpose of the study to them. Informed consent was obtained from each participant nurse. The confidentiality of their responses, and right to withdraw from the study at any time were emphasized. The participant nurses consumed about 25 minutes to fill in the questionnaires.

\subsection{Statistical Analysis}

The collected data were analyzed by Statistical Package for Social Sciences (SPSS) Software Package Version 18.0 (SPSS, Chicago, IL, USA). Data was collected, coded and organized into tables, and then analyzed using number and percent. 


\section{Results}

Table 1. Participant ICU nurses' personal characteristics No. (155)

\begin{tabular}{lclc}
\hline \multicolumn{1}{c}{ Items } & No. (\%) & \multicolumn{1}{c}{ Items } & No. (\%) \\
\hline Age & & Experience & \\
$<25$ & $66(42.6)$ & $<5$ & $97(62.6)$ \\
$25-<30$ & $53(34.2)$ & $5-<10$ & $26(16.8)$ \\
$30-35$ & $26(16.8)$ & $10-15$ & $24(15.5)$ \\
$>35 \quad$ Range & $10(6.5)$ & $>20$ & $8(5.2)$ \\
\multicolumn{1}{c}{$\quad \begin{array}{c}\text { Mean } \pm \text { SD } \\
\text { Education level }\end{array}$} & $\mathbf{2 1 - 4 0}$ & \multicolumn{1}{c}{ Range } & $\mathbf{1 - 2 8}$ \\
Bachelor degree & $135(87.1)$ & Working Unit & \\
Associate degree & $20(12.9)$ & Anesthesia ICU & $28(18.1)$ \\
Marital Status & & Cardiac ICU & $25(16.1)$ \\
Single & $54(34.8)$ & Chest ICU & $20(12.9)$ \\
Married & $101(65.2)$ & Medical ICU & $27(17.4)$ \\
Training courses last year & & Neuro. ICU & $24(15.5)$ \\
None & $60(38.7)$ & Pediatric ICU & $31(20.0)$ \\
$1-2$ & $95(61.3)$ & & \\
\hline
\end{tabular}

Table 1 shows participant ICU nurses' personal characteristics. The participant ICU nurses' age ranged between 21 up to 40 years, and the highest percent $(42.6 \%)$ of them had less than 25 years with mean $26.41 \pm 4.25$ and range $21-41$ years. Majority (87.1\%) of the nursing sample had a bachelor degree and $65.2 \%$ of them were married. More than half $(62.6 \%)$ of the participant ICU nurses had less than 5 years of experience with mean $5.14 \pm 4.99$ and range $1-28$ years. Around two fifth $(20 \%$ and $18.1 \%)$ of them worked in pediatric and anesthesia ICUs respectively. Around one third (38.7\%) of the study sample did not attained any training program last year.

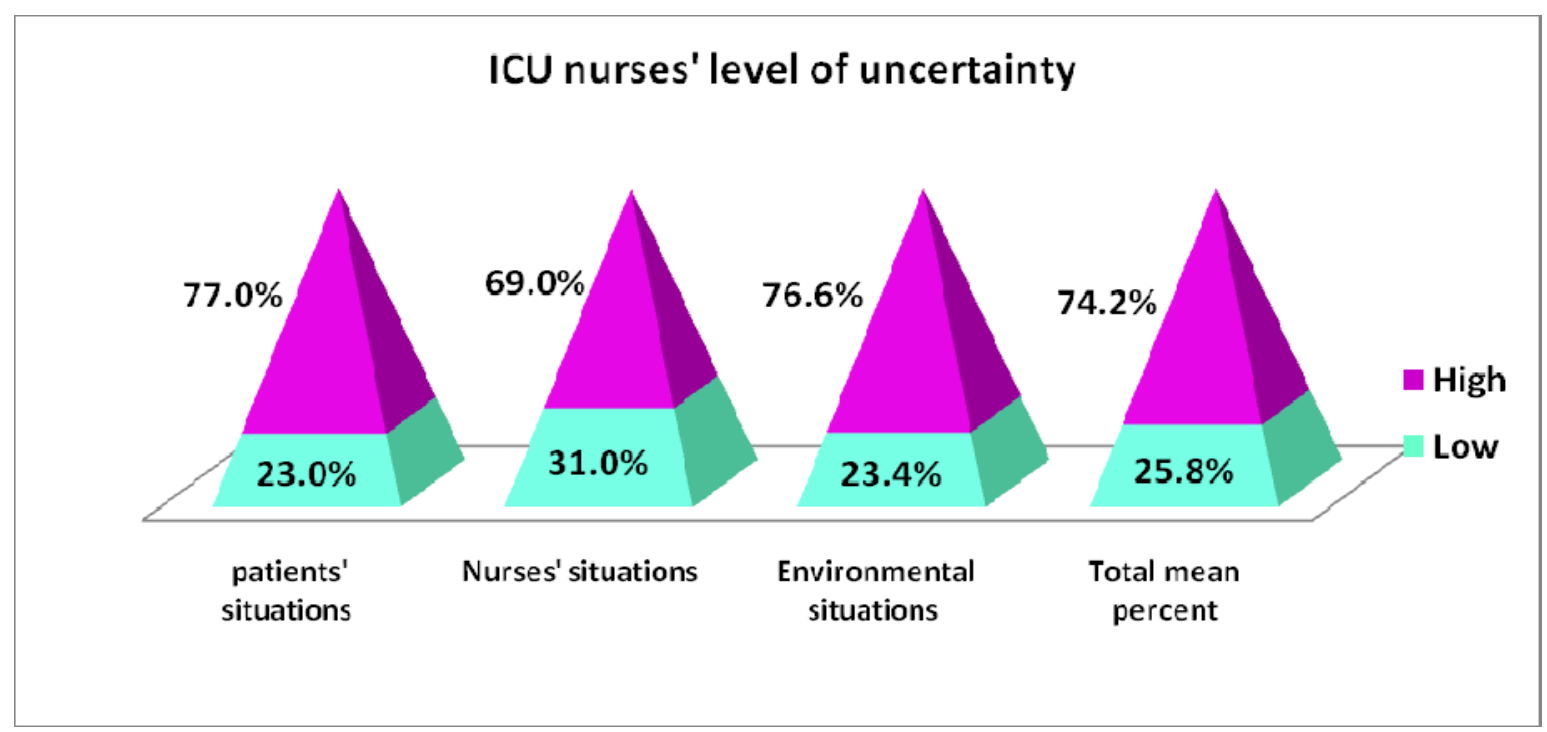

Figure 1. ICU nurses' levels of uncertainty

Figure 1 shows ICU nurses' levels of uncertainty. High percent (74.2\%) of participant ICU nurses' experienced high levels of uncertainty. More than two thirds $(77.0 \%, 76.6 \%$ and $69.0 \%)$ of ICU nurses experienced high levels of uncertainty related to patients, environment and nurses related situations respectively. 
Table 2. ICU nurses' responses to uncertainty

\begin{tabular}{lccc}
\hline \multicolumn{1}{c}{ Nurses' response to uncertainty } & $\begin{array}{c}\text { Rarely } \\
\text { No. (\%) }\end{array}$ & $\begin{array}{c}\text { Some times } \\
\text { No. (\%) }\end{array}$ & $\begin{array}{c}\text { Always } \\
\text { No. (\%) }\end{array}$ \\
\hline Uncomfortable & $10(6.5)$ & $58(37.4)$ & $87(56.1)$ \\
Confused \&loss of control & $14(9.0)$ & $54(34.8)$ & $87(56.1)$ \\
Incompetent & $16(10.3)$ & $61(39.4)$ & $78(50.3)$ \\
Embarrassed & $45(29.0)$ & $84(54.2)$ & $26(16.8)$ \\
Helpless & $52(33.6)$ & $60(38.7)$ & $43(27.7)$ \\
Tensioned & $20(12.9)$ & $80(51.6)$ & $55(35.5)$ \\
Frustrated & $28(18.1)$ & $52(330.5)$ & $75(48.4)$ \\
Emotionally drained & $10(6.5)$ & $60(38.7)$ & $85(54.8)$ \\
\hline
\end{tabular}

Table 2 shows ICU nurses' responses to uncertainty. Above half $(56.1 \%, 56.1 \%, 54.8 \%$ and $50.3 \%$ of participant ICU nurses' always experienced being uncomfortable, confused\& loss of control, emotionally drained, and incompetent as a result of facing uncertain situations in ICUs respectively. While above half of them $(54.2 \%$ and $51.6 \%)$ sometimes experienced being embarrassed and tensioned respectively.

Table 3. ICU nurses' strategies to deal with uncertainty

\begin{tabular}{lccc}
\hline \multicolumn{1}{c}{ Strategies to deal with uncertainty } & Rarely & Some times & Always \\
No. (\%) & No. (\%) & No. (\%) \\
\hline Use decision making process & $95(61.3)$ & $37(23.9)$ & $52(33.5)$ \\
Rely on intuition & $12(7.7)$ & $44(28.4)$ & $99(63.9)$ \\
Denial & $44(28.4)$ & $30(19.4)$ & $81(52.3)$ \\
Rely on evidence-based practice & $14(3.9)$ & $99(63.9)$ & $42(27.1)$ \\
Seek additional information & $10(6.5)$ & $28(18.1)$ & $117(75.5)$ \\
Team work & $6(3.9)$ & $18(11.6)$ & $131(84.5)$ \\
Figure out a plan for care & $10(6.5)$ & $98(63.2)$ & $47(30.3)$ \\
Advance capabilities (continuing education) & $8(5.2)$ & $99(63.9)$ & $48(31.0)$ \\
Use brainstorming & $10(6.5)$ & $38(24.5)$ & $107(69.0)$ \\
Learn from past experiences. & $4(2.6)$ & $32(20.6)$ & $119(76.8)$ \\
\hline
\end{tabular}

Table 3 illustrates ICU nurses' strategies to deal with uncertainty. More than three quarters $(84.5 \%, 76.8 \%$, $75.5 \%, 69 \%$ and $63.9 \%$ ) of ICU nurses' sample always used team work, learn from past experience, seeking additional information, use brainstorming and rely on intuition as strategies to deal with uncertain situations in ICUs respectively. While the least frequently used strategies to deal with uncertainty were rely on evidence-based practice, figuring out a plan for care, advance personal capabilities through continuing education, and using decision making process $(27.1 \%, 30.3 \%, 31 \%$, and $33.3 \%)$ respectively.

Table 4. Nurses' evaluation of patient safety culture in their ICUs

\begin{tabular}{lcccc}
\hline \multicolumn{1}{c}{ ICUs (Total No.) } & $\begin{array}{c}\text { Nurses evaluation of patient safety in ICUs } \\
\text { Bad } \\
\text { No. (\%) }\end{array}$ & $\begin{array}{c}\text { Aceptable } \\
\text { No. (\%) }\end{array}$ & $\begin{array}{c}\text { Good } \\
\text { No. (\%) }\end{array}$ & $\begin{array}{c}\mathbf{X}^{\mathbf{2}} \\
\text { (P value) }\end{array}$ \\
\hline Anesthesia ICU (28) & $4(14.3)$ & $12(42.9)$ & $12(42.8)$ \\
Cardiac ICU (25) & $6(24.0)$ & $3(12.0)$ & $16(64.0)$ & $13(65.0)$ \\
Chest ICU (20) & $1(5.0)$ & $6(30.0)$ & $17(62.9)$ & 35.030 \\
Medical ICU (27) & $3(11.1)$ & $7(25.9)$ & $5(20.8)$ & $\left(0.020^{*}\right)$ \\
Neuro. ICU (24) & $3(12.5)$ & $16(66.7)$ & $19(61.3)$ & \\
Pediatric ICU (31) & $3(9.7)$ & $9(29.0)$ & $82(52.9)$ & \\
\multicolumn{1}{c}{ Total (155) } & $20(12.9)$ & $53(34.2)$ & &
\end{tabular}

$\mathrm{P}<0.05$ Significant 
Table 4 shows nurses' evaluation of patient safety culture in their ICUs. Around half (52.9\%) of the participated ICU nurses evaluated the patient safety culture in their working units as good, while around half (47.1\%) of them evaluated the patient safety culture as acceptable and bad. High percent $(65 \%, 64 \%, 62.9 \%$ and $61.3 \%)$ of chest, cardiac, medical and pediatric ICU nurses evaluated the patient safety culture as a good respectively. At the same time high percent $(79.2 \%$ and $57.2 \%$ ) of neurology and anesthesia ICU nurses respectively evaluated patient safety culture as a bad and acceptable in their units. The table also reveals a statistical significant difference between nurses' evaluation of patient safety culture according to their working ICUs at ( $p$-value $=0.020$ ).

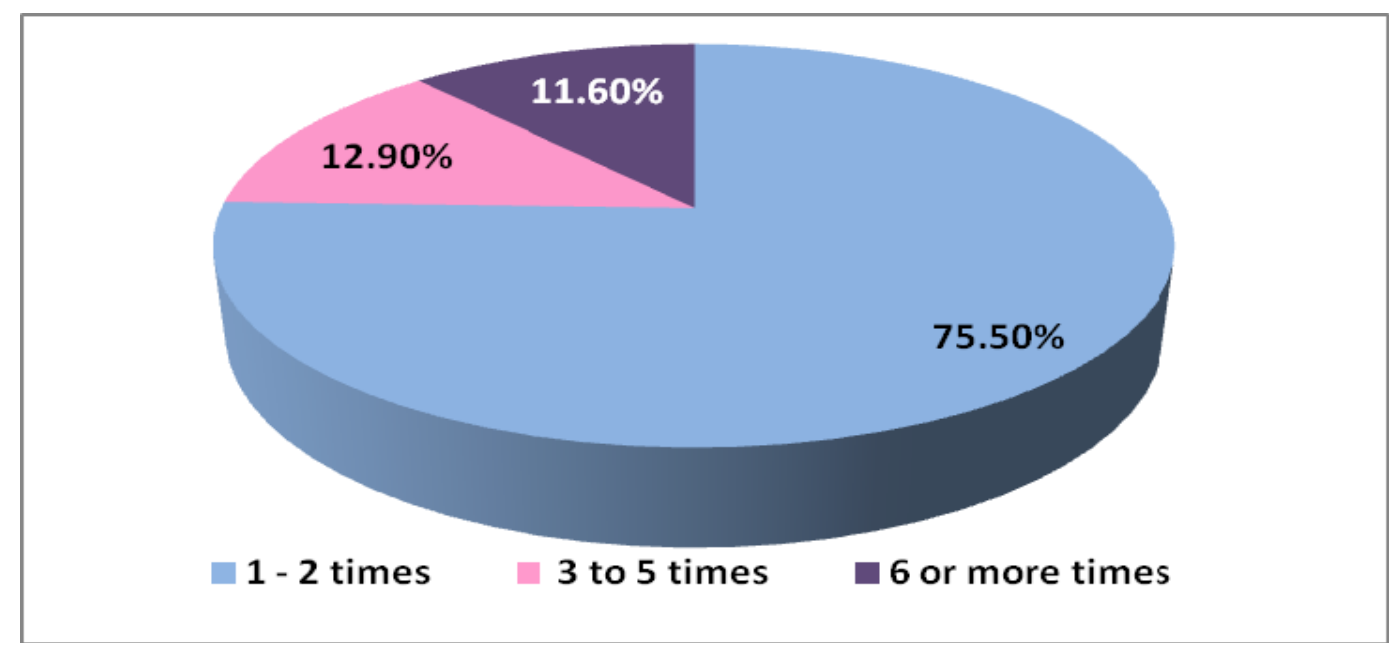

Figure 2. Frequency of reporting negative events by ICU nurses during last year

Figure 2 shows frequency of reporting negative events by ICU nurses during last year. Three quarters $(75.5 \%)$ of the participated ICU nurses reported negative events in their ICU between 1 to 2 times last year, while $(11.6 \%)$ reported 6 or more times the negative events in their ICU during last year.

Table 5. ICU nurses' perception of patient safety culture dimensions

\begin{tabular}{|c|c|c|c|c|c|c|c|}
\hline Patient Safety Dimensions & \multicolumn{3}{|c|}{ Range } & Mean & $\underline{ \pm}$ & SD & Mean \% \\
\hline Continuous improvement & 1.00 & - & 3.00 & 2.15 & \pm & 0.50 & $69.0 \%$ \\
\hline Intra-unit teamwork & 1.00 & - & 3.00 & 2.29 & \pm & 0.46 & $83.2 \%$ \\
\hline Staff availability \& work conditions & 1.00 & - & 2.75 & 2.02 & \pm & 0.41 & $65.2 \%$ \\
\hline Supervisory measures to sustain safety & 1.00 & - & 3.00 & 2.01 & \pm & 0.39 & $63.2 \%$ \\
\hline Feedback regarding errors & 1.00 & - & 3.00 & 1.95 & \pm & 0.55 & $54.8 \%$ \\
\hline Inter units teamwork & 1.00 & - & 3.00 & 2.05 & \pm & 0.52 & $69.0 \%$ \\
\hline Open channels of communication & 1.00 & - & 3.00 & 1.76 & \pm & 0.46 & $36.1 \%$ \\
\hline Organizational awareness of safety & 1.25 & - & 3.00 & 2.18 & \pm & 0.39 & $79.4 \%$ \\
\hline Management role to sustain safety & 1.33 & - & 3.00 & 1.98 & \pm & 0.42 & $62.6 \%$ \\
\hline Control patient transition \& handoffs & 1.00 & - & 3.00 & 2.37 & $\underline{+}$ & 0.50 & $85.8 \%$ \\
\hline Response to error & 1.00 & - & 3.00 & 1.87 & \pm & 0.56 & $48.4 \%$ \\
\hline Total Safety Scale & 1.44 & - & 2.54 & 2.07 & \pm & 0.22 & $? ? ? ?$ \\
\hline
\end{tabular}

Table 5 represents ICU nurses' perception of patient safety culture dimensions. The nurses' highest positive mean score percent of patient safety culture dimension were $(85.8 \%, 83.2 \%$, and $79.4 \%)$ regarding control patient transition \& handoffs, intra unit teamwork, and organizational awareness of safety respectively. On the other hand the lowest positive mean score percent of patient safety culture dimension $(36.1 \%, 48.4 \%$, and $54.8 \%)$ were regarding open channels of communication, response to error, and feedback regarding error respectively. 
Table 6. Correlation between patients' safety culture and ICU nurses experiencing uncertainty

\begin{tabular}{|c|c|c|c|c|c|c|c|}
\hline \multirow{2}{*}{$\begin{array}{l}\text { Working Unit } \\
\text { (Total no.) }\end{array}$} & \multicolumn{2}{|c|}{ Patients' safety } & \multirow{2}{*}{$\begin{array}{c}\mathbf{X}^{2} \\
\text { (P value) }\end{array}$} & \multicolumn{2}{|c|}{$\begin{array}{l}\text { Experiencing } \\
\text { Uncertainty }\end{array}$} & \multirow{2}{*}{$\begin{array}{c}\mathbf{X}^{2} \\
(\mathbf{P} \\
\text { value })\end{array}$} & \multirow{2}{*}{$\begin{array}{c}\text { Spearman's } \\
\text { rho } \\
\text { (P-value) }\end{array}$} \\
\hline & $\begin{array}{c}\text { Low } \\
\text { No. }(\%) \\
\end{array}$ & $\begin{array}{c}\text { High } \\
\text { No. }(\%) \\
\end{array}$ & & $\begin{array}{c}\text { Low } \\
\text { No. }(\%) \\
\end{array}$ & $\begin{array}{c}\text { High } \\
\text { No. }(\%) \\
\end{array}$ & & \\
\hline $\begin{array}{l}\text { ICU anesthesia } \\
\text { (28) }\end{array}$ & $16(57.1)$ & $12(42.9)$ & \multirow{7}{*}{$\begin{array}{c}16.92 \\
\left(0.005^{* *}\right)\end{array}$} & $6(21.4)$ & $22(78.6)$ & \multirow{7}{*}{$\begin{array}{c}9.87 \\
(.079 *)\end{array}$} & \multirow{7}{*}{$\begin{array}{l}-0.31^{* *} \\
(0.000)\end{array}$} \\
\hline ICU cardiac (25) & $5(20.0)$ & $20(80.0)$ & & $14(56.0)$ & $11(44.0)$ & & \\
\hline ICU chest (20) & $4(20.0)$ & $16(80.0)$ & & $8(40.0)$ & $12(60.0)$ & & \\
\hline ICU medical (27) & $6(22.2)$ & $21(77.8)$ & & $11(40.7)$ & $16(59.3)$ & & \\
\hline $\begin{array}{l}\text { ICU neurology } \\
\text { (24) }\end{array}$ & $13(54.2)$ & $11(45.8)$ & & $8(33.3)$ & $16(66.7)$ & & \\
\hline ICU pediatric (31) & $9(29.0)$ & $22(71.0)$ & & $7(22.6)$ & $24(77.4)$ & & \\
\hline Total (155) & $53(34.2 \%)$ & $102(65.8 \%)$ & & $54(34.8)$ & $101(65.2)$ & & \\
\hline
\end{tabular}

** $\mathrm{P}<0.01$ Highly Significant * $\mathrm{P}<0.05$ Almost Significant

Table 6 shows correlation between patients' safety culture and ICU nurses experiencing uncertainty. The table reveals there was high significant correlation between the level of patient safety culture and experiencing uncertainty by ICU nurses'. The table also shows the lowest levels of patient safety culture were $(57.1 \%, 54.2 \%$ and 29\%) in anesthesia, neurology and pediatric ICUs respectively. Also the highest levels of uncertainty experienced by ICU nurses $(78.6 \%, 77.4 \%$ and $66.7 \%)$ were in anesthesia, pediatric and neurology ICUs respectively.

Table 7. Correlation between patient safety culture, ICU nurses' experiencing uncertainty, their response and strategies used to deal with uncertainty

\begin{tabular}{lccc}
\hline \multicolumn{1}{c}{ Scales } & $\begin{array}{c}\text { Experiencing } \\
\text { Uncertainty }\end{array}$ & $\begin{array}{c}\text { Response to } \\
\text { uncertainty }\end{array}$ & $\begin{array}{c}\text { Strategies to } \\
\text { deal with } \\
\text { uncertainty }\end{array}$ \\
\hline Patient safety culture & $-.306^{* *}$ & -.112 & $.211^{* *}$ \\
& .000 & .166 & .008 \\
Experiencing Uncertainty & & $.246^{* *}$ & -.016 \\
& & .002 & .840 \\
Response to uncertainty & & & .084 \\
\hline Highly Significant & & & .298 \\
\hline
\end{tabular}

Table 7 shows correlation between patient safety culture, nurses' experiencing uncertainty, their response and strategies used to deal with uncertainty. The table reveals high statistical significant negative correlation between patient safety culture and ICU nurses' experiencing clinical uncertainty at $p=0.000$. There were high significant correlation between nurses' experiencing uncertainty and their response to uncertainty, as well as between patient safety culture and strategies used by nurses to deal with uncertainty. 
Table 8. Correlations of the Patients Safety culture dimensions

\begin{tabular}{|c|c|c|c|c|c|c|c|c|c|c|}
\hline Patients Safety culture dimensions & 1 & 2 & 3 & 4 & 5 & 6 & 7 & 8 & 9 & 10 \\
\hline \multirow[t]{2}{*}{ Continuous improvement } & $.528^{* *}$ & $.226^{* *}$ & .120 & $.239^{* *}$ & $.338^{* *}$ & .056 & $.383^{* *}$ & $.192^{*}$ & .152 & -.137 \\
\hline & .000 & .005 & .138 & .003 & .000 & .492 & .000 & .016 & .058 & .089 \\
\hline \multirow[t]{2}{*}{ Intra-unit teamwork } & & $.311^{* *}$ & $299^{* *}$ & $.263^{* *}$ & $.272^{* *}$ & .043 & $.428^{* *}$ & $.238^{* *}$ & .094 & -.156 \\
\hline & & .000 & .000 & .001 & .001 & .592 & .000 & .003 & .242 & .052 \\
\hline \multirow[t]{2}{*}{ Staff availability \& work conditions } & & & $.179^{*}$ & $.224^{* *}$ & $.206^{*}$ & .038 & $.190^{*}$ & .046 & $.298^{* *}$ & -.017 \\
\hline & & & .026 & .005 & .010 & 639 & .018 & .570 & .000 & .831 \\
\hline \multirow[t]{2}{*}{ Supervisory measures to safety } & & & & $.231^{* *}$ & $.219^{* *}$ & .076 & .157 & .089 & -.110 & $-.248^{* *}$ \\
\hline & & & & .004 & .006 & 348 & .050 & 272 & .173 & .002 \\
\hline \multirow[t]{2}{*}{ Feedback regarding errors } & & & & & $.318^{* *}$ & .077 & $.312^{* *}$ & .049 & .073 & -.136 \\
\hline & & & & & .000 & 342 & .000 & .541 & .364 & .091 \\
\hline \multirow[t]{2}{*}{ Inter units teamwork } & & & & & & -.041 & $.307^{* *}$ & .148 & $.234^{* *}$ & -.019 \\
\hline & & & & & & .609 & .000 & .066 & .003 & .817 \\
\hline \multirow[t]{2}{*}{ Open channels of communication } & & & & & & & .100 & .093 & -.009 & .020 \\
\hline & & & & & & & 217 & .248 & .912 & .804 \\
\hline \multirow[t]{2}{*}{ Organizational awareness of safety } & & & & & & & & $265^{* *}$ & $.220^{* *}$ & -.152 \\
\hline & & & & & & & & .001 & .006 & .060 \\
\hline \multirow[t]{2}{*}{ Management role to sustain safety } & & & & & & & & & $.242^{* *}$ & -.089 \\
\hline & & & & & & & & & .002 & .268 \\
\hline Control patient transition \& & & & & & & & & & & .141 \\
\hline handoffs & & & & & & & & & & .081 \\
\hline
\end{tabular}

Table 8 shows correlations of the patients' safety culture dimensions. The table reveals statistical significant correlation between all patient safety culture dimensions except for open channels of communication, management role to sustain safety, and response to error.

\section{Discussion}

High percent of participant ICU nurses' experienced high levels of uncertainty. More than two thirds of the studied ICU nurses experienced high levels of uncertainty regarding patients', environment and nurses' related situations. These results seem to be logic where ICU nurses provide care for critically ill patients with unstable health status; consequently patient care related decisions include high levels of risk. Furthermore, ICU nurses confronted with many challenges as interdependence between multidisciplinary healthcare team, dealing with technological and sophisticated equipments and shortage of time and staff. Confirming to our study results (Schreyögg and Ostermann, 2014) and (Braun, 2010) found that ICUs comprise high degree of uncertainty. Also (Cioffi, 2000; Wichowski \& Kubsch, 1995; Bucknall, 2003; and Charleston \& Happell, 2005) reported that nurses experiencing clinical uncertainty emerged from facing unusual patient situations, dealing with unfamiliar procedures and technology, incoherent information and lack of knowledge.

Present study results showed above half of participated ICU nurses' always experienced being uncomfortable, confused\& loss of control, emotionally drained, and incompetent as a result of facing uncertain situations in ICUs. While above half of them sometimes experienced being embarrassed and tensioned. These results can be interpreted as ICU nurses face excessive amounts of stress emerged from shortage of time and information, as well as instability of patient condition that required responding quickly and efficiently. Moreover around two thirds of our study ICU nurses had less than five years of experience, that make them unable to handle difficult situations. In total ICU nurses feel tense and doubt their competencies that will jeopardize the quality of patient care plus safety. The results of the present study go in the same line with (Cranley, 2009) who found that nurses experienced negative emotions when being faced with uncertain and infrequent patient condition including being uncomfortable, insecure; anxious in their decisions and actions; and being insufficient as they lack information or clinical knowledge. Also (Sayed and Ibrahim, 2012; and Vivian\& Luiz, 2009) found that experiencing clinical uncertainty was the most common source of ICU nurses stress. Vaismoradi et al. (2011) reviled that Iranian 
nursing sample as a consequence of facing uncertainty in clinical practice they experienced negative feelings include anxiety, fear, anger, and frustration.

Our study results pointed out more than three quarters of ICU nurses' always used team-work, learn from past experience, seeking additional information, brainstorming and rely on intuition as strategies to deal with uncertain situations in ICUs. While the least frequently used strategies to deal with uncertain situations including rely on evidence-based practice, figuring out a plan for care, advance personal capabilities through continuing education, and using decision making process. These results illustrate that the studied ICU nurses depend on colleagues support and available information and experience more than depending on evidence-based information and critical thinking. This may be related to limited opportunities for improvement where around one third of them did not receive any training program last year as viewed in table1. In addition, increased workload in ICUs, and unavailability of authorized referral committee to analyze uncertain situations and disseminate the appropriate solutions.

These results are supported by (Benner, 2001) assumed that intuition is an essential element of professional judgment; during practice; based on experience. Also intuition enables professionals' to react to complex situations rabidly, efficiently, and unconsciously. In addition (Rew, 2000; and Gigerenzer, 2007) stated that intuition is developed as a response to the limited capacity of human mind to deal with uncertain situations in practice. They found that their study group was more doing well in forecasting the performance of shares than the more sophisticated experts relying on sophisticated information.

A key finding from previous studies revealed that seeking additional information reduces levels of clinical uncertainty (Cranley, 2009; MacIntosh-Murray \& Choo, 2005). Whereas (O'Connell, 2000) found that nurses make sense of the situation to minimize uncertainty by adapting work practices through collecting required information and prioritize patient care plan. While (Cioffi, 1998; Benner et al., 1999; and Hedberg \& Larsson, 2003) found that nurses rely on experience to make their clinical decisions when facing uncertain situation. Adding to that (Carr et al., 2001) found that to buffer the effect of uncertainty nurses participate patients in decision-making if collaboration with colleagues was not available. Furthermore (Hedberg and Larsson, 2003) found that collaboration with colleagues and information gathering reduce nurses' uncertainty. Also (Vaismoradi et al., 2011) revealed that losing sensitivity and avoiding trouble practice were main strategies nurses used to deal with uncertain situations in practice.

Around half of the participated ICU nurses evaluated patient safety culture in their working units as acceptable and bad. Considerable percent of neurology and anesthesia ICUs' nurses evaluated patient safety as a bad and acceptable in their units. There was a significant difference between nurses' evaluation of patient safety according to their working ICUs. These results may be due to inappropriate nurse patient ratio, and increased workload that put ICU patients at risk and make them prone to nursing care errors. Moreover, majority of patients in neurology and anesthesia ICUs are comatosed and ventilated requiring intense care. Beccaria et al., (2009) stated that ICUs are considered the most susceptible hospital areas for adverse events, incidents and errors in nursing care, where severely ill patients are cared for. Also a study conducted by (Nicklin and McVeety, 2002) found that the participant Canadian nurses perceived that health care environment, in which they provide care, shows increasing risk to their patients. In the same line (Claro et al., 2011) found that high percent of their study nurses reported the existence of adverse events in their ICUs.

Three quarters of the study nurses sample reported negative events in their ICU between 1 to 2 times last year, while one tenth reported 6 or more times the negative events in their ICU during last year. Occurrence of negative and adverse events in intensive care units is undeniable fact that healthcare administrators should face to increase the quality of patient care. ICU nurses experiencing high work load, lack of supplies and equipments, and did not receive adequate training. Reporting adverse events help administrators to estimate the overall incidences and understand the underlying causes and to find ways to prevent future events. But this depends mainly on the non-punitive environment to errors, to encourage nurses' reporting of errors.

Our study results were confirmed by (Ferner, 2009) found that underreporting of adverse events is common, as a result of staff lack of awareness of the error, or fear of punishment. Kiekkas et al., (2011) argued that reporting of incidents varies where individual more likely to report incidents related to organizational deficiency rather than personal deficiency to protect self-esteem. Forster et al., (2008) found that around one fifth of the ICU patients experienced adverse event and one fifth of it was considered preventable. Moreover (Claro et al., 2011) stated that more than half of ICU nurses sometimes reported adverse events in their ICUs.

Our studied ICU nurses' highest positive mean score of patient safety dimensions were regarding control patient transition \& handoffs, intra-unit teamwork, and organizational awareness of safety. While their lowest mean 
score of patient safety culture dimensions were regarding open channels of communication, response to error, and feedback regarding errors. These results are reassuring where ICU nurses perceived patient transition as smooth process; no missing can affect patient condition; this can be supported by team work, staff awareness and conviction of patient safety, and integration between hospital units. On the other hand the participated ICU nurses viewed that communication problems, punitive response to error, and lack of feedback about error endanger patients' safety culture. Go in the same line with our results (Aboul-Fotouh, 2012) found that the highest positive mean score was concerning organizational learning, followed by teamwork dimension and the lowest mean score was for non-punitive response to error.

Findings of present study reveal high significant correlation between the level of patient safety culture and experiencing uncertainty by ICU nurses'. The highest levels of uncertainty experienced by ICU nurses were in anesthesia, neurology and pediatric ICUs. Also the lowest levels of patient safety were in the same ICUs. These results are logic where patient in anesthesia, neurology and pediatric ICUs were critically ill and majority of them were mechanically ventilated and their health status is unstable and unpredictable. On the same line with our study results (Thompson and Yang, 2009) found a significant correlation between patient safety and experiencing uncertainty. Kang (2005) revealed that there was an association between uncertainty and patients' health status. Nicklin \& McVeety (2002) found that Canadian nurses perceived that healthcare environment uncertainty jeopardize patient safety. Also (Simmons, 2010; Penrod, 2007; and Rabey, 2006) found that experiencing clinical uncertainty put patient safety and their quality of care at risk.

Our findings revealed a high statistical significant negative correlation between patient safety culture and nurses' experiencing uncertainty. Also there were high significant correlation between nurses' experiencing uncertainty and their response to uncertainty, and between patient safety culture and strategies used by nurses to deal with uncertainty. These results are logic where the higher the level of uncertainty the lower the level of patient safety culture. Adding to that the more suitable the strategies used by ICU nurses to buffer the effect of uncertainty the more safely the patient culture is. These findings are congruent with (Cranley, 2009) who found that experiencing clinical uncertainty by nurses have a profound effect on their clinical decision making, ethical as well as procedural aspects of patient care. Scott et al., (2008); Estabrooks et al., (2005); McCaughan et al., (2005) reported that nurses there were a correlation between strategies used by nurses to decrease the level of uncertainty such as collaboration with colleagues, rely on their clinical experience and patient care quality and safety.

\section{Conclusion}

Overall level of uncertainty of ICU nurses' at Tanta Main University Hospital was high. They experienced high level of uncertainty regarding patient, environment, and nurses situations. Consequently they feel being uncomfortable, confused \& loss of control, emotionally drained, and incompetent. ICU nurses always used team work, learn from past experience. The least frequently used strategies to deal with uncertainty were rely on evidence-based practice, figuring out a plan for care, advance personal capabilities through continuing education, and using decision making process. High percent of ICU nurses evaluated the patient safety culture in their working units as good. But they had low perception communication openness, non-punitive response to error, and feedback about error dimensions of patient safety culture. High statistical significant negative correlation was found between patient safety culture and experiencing uncertainty by ICU nurses. There were high significant correlation between nurses' experiencing uncertainty and their response to uncertainty, as well as between patient safety culture and ICU nurses strategies to deal with uncertainty.

Thus, we recommend:

1. Nurse Managers need to establish in-service education programs for ICU nurses about how to manage clinical uncertainty and patient safety culture.

2. Faculty of Nursing requires addressing sources of uncertainty among nursing students.

3. Healthcare managers need to establish a committee to ascertain patient safety culture focusing on communication, response to error, and feedback regarding error, as well as set guidelines for nurses to deal with uncertainty.

4. Further monitoring of patient safety culture in ICUs is required.

\section{Acknowledgements}

The researchers would like to thank the participated intensive care unit nurses at Tanta University Main Hospital. 


\section{References}

Aboul-Fotouh, A.M., Ismail, N.A., Ez Elarab, H.S., \& Wassif, G.O. (2012). Assessment of patient safety culture among healthcare providers at a teaching hospital in Cairo, Egypt. EMHJ, 18(4), 372.

Agency for Healthcare Research and Quality. (2008). National Healthcare Quality and Disparities Reports. Rockville, Maryland.

Arun, T., Sharad, G., Gagare, A.G., \& Amit, T. (2015). Medical Uncertainty: Are We Better Off In Era OF Evidence Based Medicine? Int J Med Res Health Sci., 4(1), 208-213. https://doi.org/10.5958/2319-5886.2015.00034.X

Beccaria, L.M., Pereira, R.A.M., Contrin, L.M., Lobo, S.M.A., \& Trajano, D.H.L. (2009). Eventos adversos na assistência de enfermagem em uma unidade de terapia intensiva. Rev Bras Ter Intensiva, 21(3), 276-82. https://doi.org/10.1590/S0103-507X2009000300007

Benner, P. (2001). From Novice to Expert: Excellence and Power in Clinical Nursing Practice. Prentice Hall.

Benner, P., Hooper-Kyriakidis, P., \& Stannard, D. (1999). Clinical wisdom and interventions in critical care: A Thinking in Action Approach. London: W.B. Saunders.

Braun, J.P. (2010). Intensivmedizinische Peer Reviews: Qualitätsinitiative für Ärzte und Patienten. Deutsches Ärzteblatt, 107(41).

Bucknall, T. (2003). The clinical landscape of critical care: Nurses' decision making. Journal of Advanced Nursing, 43(3), 310-319. https://doi.org/10.1046/j.1365-2648.2003.02714.x

Carr, S.M., Bell, B., Pearson, P.H., \& Watson, D.W. (2001). To be sure or not to be sure: Concepts of uncertainty and risk in the construction of community nursing practice. Primary Health Care Research and Development, 2, 223-233. https://doi.org/10.1191/146342301682157700

Charleston, R., \& Happell, B. (2005). Coping with uncertainty within the preceptorship experience: The perceptions of nursing students. Journal of Psychiatric and Mental Health Nursing, 12(3), 303-309. https://doi.org/10.1111/j.1365-2850.2005.00837.x

Cioffi, J. (1998). Decision-making by emergency nurses in triage assessments. Accident and Emergency Nursing, 6, 184-191. https://doi.org/10.1016/S0965-2302(98)90077-7

Cioffi, J. (2000). Nurses' experiences of making decisions to call emergency assistance to their patients. Journal of Advanced Nursing, 32, 108-114. https://doi.org/10.1046/j.1365-2648.2000.01414.x

Claro, C., Krocockz, D., Toffolleto, M., \& Padilha, K. (2011). Adverse events at the Intensive Care Unit: nurses' perception about the culture of no-punishment. Rev Esc Enferm USP, 45(1), 162-167.

Cranley, L.A. (2009). A Grounded theory of intensive care nurses' experiences and responses to uncertainty. Doctor of Philosophy, Nursing Science University of Toronto.

Estabrooks, C.A., Chong, H., Brigidear, K., \& Profetto-McGrath, J. (2005). Profiling Canadian nurses' preferred knowledge sources for clinical practice. Canadian Journal of Nursing Research, 37, 119-139.

Ferner, R.E. (2009). The epidemiology of medication errors: the methodological difficulties. Br. J. Clin. Pharmacol, 67, 614-620. https://doi.org/10.1111/j.1365-2125.2009.03417

Forster, A., Kyeremanteng, K., Hooper, J., Shojania, K., \& Walraven, C. (2008). The impact of adverse events in the intensive care unit on hospital mortality and length of stay. BMC Health Serv Res, 8, 259. https://doi.org/10.1186/1472-6963-8-259

Gigerenzer, G. (2007). Gut Feelings. New York: Viking.

Grote, G. (2009). Defining and Identifying Uncertainties in Organizations. Retrieved from ww.springer.com/cda/.../9781848823723-c1.pdf?

Hedberg, B., \& Larsson, U.S. (2003). Observations, confirmations and strategies-Useful tools in decision making process for nurses in practice?. Journal of Clinical Nursing, 12, 215-222. https://doi.org/10.1046/j.1365-2702.2003.00703.x

Kang, Y. (2005). Effects of uncertainty on perceived health status in patients with atrial fibrillation. British Association of Critical Care Nurses. Nursing in Critical Care, 10(4), 184-194. https://doi.org/10.1111/j.1362-1017.2005.00100.x 
Kiekkas, P., Karga, M., Lemonidou, C., Aretha, D., \& Karanikolas, M. (2011). Medication errors in critically ill adults: a review of direct observation evidence. Am. J. Crit. Care, 20, 36-44. https://doi.org/10.4037/ajcc2011331

LeGuin, U. (2013). Diagnosing \& engaging with complex environmental problems. John Ruter.

MacIntosh-Murray, A., \& Choo, C.W. (2005). Information behaviour in the context of improving patient safety. Journal of the American Society for Information Science and Technology, 56, 1332-1345. https://doi.org/10.1002/asi.20228

McCaughan, D., Thompson, C., Cullum, N., Sheldon, T., \& Raynor, P. (2005). Nurse practitioner and practice nurses' use of research information in clinical decision making: Findings from an exploratory study. Family Practice, 22, 490-497. https://doi.org/10.1093/fampra/cmi042

McGonigal-Kenney, M.L. (2011). An intangible reality: the experience of uncertainty among intimate partners of persons with prodromal huntington disease. $\mathrm{PhD}$ (Doctor of Philosophy) thesis, University of Iowa.

Nicklin, W., \& McVeety, J. (2002). Canadian nurses' perceptions of patient safety in hospitals. Canadian Journal of Nursing Leadership, 15(3), 1-11. https://doi.org/10.12927/cjnl.2002.19154

O’Connell, B. (2000). Enabling care: Working through obscurity and uncertainty-A basic social process used in selected acute care settings. Australian Journal of Advanced Nursing, 17, 32-39.

Penrod, J. (2007). Living with uncertainty: concept advancement. Journal of Advanced Nursing, 57(6), 658-667. https://doi.org/10.1111/j.1365-2648.2006.04008.x

Rabey, G.P. (2006). Response to uncertainty. Team Performance Management, 12(3/4), 77-81. https://doi.org/10.1108/13527590610674086

Rew, L. (2000). Acknowledging Intuition in Clinical Decision Making. Journal of Holistic Nursing, 18(2), 94-108. https://doi.org/10.1177/089801010001800202

Sayed, H., \& Ibrahim, M. (2012). Stressors among Nursing Staff Working in Intensive Care Unit in Governmental \& Non-governmental Hospitals at Makkah Al-Moukarramah, KSA. Journal of American Science, 8(6), 25-31. Retrieved from http://www.sciencepub.net/american.3

Schreyögg, G., \& Ostermann, S. (2014). Managing uncertainty in Intensive Care Units-Exploring formal and informal coping practices in a university hospital. Freie Universita et Berlin, Institute of Management, School of Business \& $\quad$ Economics. $\quad$ Retrieved from http://www.egosnet.org/jart/prj3/egos/resources/dbcon_def/uploads/qACNR_ManaginguncertaintyinIntensi veCareUnits.pdf

Scott, S.D., Estabrooks, C.A., Allen, M., \& Pollock, C. (2008). A context of uncertainty: How context shapes nurses' research utilization behaviors. Qualitative Health Research, 18, $347-357$. https://doi.org/10.1177/1049732307313354

Sheer, V.C., \& Cline, R.J. (1995). Testing a model of perceived information adequacy and uncertainty reduction in physician-patient interactions. Journal of Applied Communication Research. https://doi.org/10.1080/00909889509365413

Simmons, B. (2010) Clinical reasoning: concept analysis. Journal of Advanced Nursing, 66(5), 1151-1158. https://doi.org/10.1111/j.1365-2648.2010.05262.x

Striefel, S.S. (2006). Professional issues: uncertainties in daily practice. Association for Applied Psychophysiology \& Biofeedback, 34(4), winter, 123-126. Retrieved from www.aapb.org

Thompson, C., \& Dowding, D. (2001). Responding to uncertainty in nursing practice. International Journal of Nursing Studies, 38, 609-615. https://doi.org/10.1016/S0020-7489(00)00103-6

Thompson, C., \& Yang, H. (2009). Nurses' decisions, irreducible uncertainty and maximizing nurses' contribution to patient safety. Healthcare quality, 12, 178-185. https://doi.org/10.12927/hcq.2009.20946

Vaismoradi, M., Salsali, M., \& Ahmadi, F. (2011) Nurses' experiences of uncertainty in clinical practice: a descriptive study. Journal of Advanced Nursing, 691-999. https://doi.org/10.1111/j.1365-2648.2010.05547.x

Vivian, A.P., \& Luiz, J.P. (2009). Stress among nurses who work at the intensive care unit. Rev. Esc. Enferm USP, 43(4), 365-372. 
Wichowski, H.C., \& Kubsch, S. (1995). How nurses react to and cope with the uncertainty ofunfamiliar technology: Validation for continuing education. The Journal of Continuing Education in Nursing, 26(4), 174-178.

\section{Copyrights}

Copyright for this article is retained by the author(s), with first publication rights granted to the journal.

This is an open-access article distributed under the terms and conditions of the Creative Commons Attribution license (http://creativecommons.org/licenses/by/4.0/). 